\title{
The Ouroboros of Seeking Validation? Exploring the Interconnection of Appearance (Dis)satisfaction and Content Creation on Social Media
}

\author{
Erica Åberg and Aki Koivula
}

Ouroboros is an ancient Egyptian symbol depicting a serpent or dragon devouring its tail. The origin of this motif is ancient Egyptian iconography, and it is often interpreted as a symbol of eternal cyclic renewal or a cycle of life, death and rebirth. The earliest, first known example of the true Ouroboros icon is on the second gold shrine of Tutankhamun, where they are seen surrounding a large mummiform figure, a representation of the unified reborn Re-Osiris (Reemes, 2015). The connection between ancient Egypt and social media may seem a bit distant at first glance. However, a snake devouring its tail is a concept that captures the intention of this chapter: to elaborate the possible motives for people to create content on social media, yearning for comments and likes to be reborn, but also becoming accustomed to receiving positive feedback. This eternal cycle may be essential to describe individuals in an appearance-oriented society, creating content on social media, seeking validation and multiplying the audiences of their aesthetic performances.

In this chapter, we use the concept of aesthetic capital to illustrate how appearance-related assets are displayed and controlled, but also accumulated and utilised on social media platforms. Social media offers its users endless possibilities to fulfil the desires of the 'performing self' (Featherstone, 1982), a person preoccupied with a stylised presentation, impression management and versatile self-expression. The visual and textual expressions on social networking sites intend to give off impressions about the self, as well as advance particular narratives about one's life and identity for a particular audience, most often for peers (boyd, 2008; Dobson, 2016). Regardless of the 'mediated public' (boyd, 2008), the

\footnotetext{
Appearance as Capital, 117-134

Copyright (C) 2022 Erica Åberg and Aki Koivula

Published by Emerald Publishing Limited. These works are published under the Creative

Commons Attribution (CC BY 4.0) licence. Anyone may reproduce, distribute, translate and create derivative works of these works (for both commercial and non-commercial purposes), subject to full attribution to the original publication and authors. The full terms of this licence may be seen at http://creativecommons.org/licences/by/4.0/legalcode doi: $10.1108 / 978-1-80043-708-120210008$
} 


\section{Erica Åberg and Aki Koivula}

performance of appropriately presenting oneself to one's audience in daily life remains similar to that of offline, that is, through clothing, speech and embodiment.

However, despite being offered various modes of presentation, platforms and audiences, that appearance performer may remain unfulfilled in terms of attention, gratification and accumulating appearance-related resources in consumer society. Previous literature has indeed established that social media use predominantly leads to negative individual-level outcomes: increased appearance pressures (e.g. Åberg, Koivula, \& Kukkonen, 2020), body image concerns and disordered eating (for a systematic review, see Holland \& Tiggemann, 2016). However, these findings do not apply similarly to all social media users, as the propensity to report social media as a source of appearance-related strains is higher especially for younger women (e.g. Fardouly et al., 2015; Tiggemann \& Miller, 2010; Tiggemann \& Slater, 2013). More recent studies have identified these concerns as being specifically more prevalent among the female users of Instagram (e.g. Tiggemann et al., 2020b; Aberg, Koivula, \& Kukkonen, 2020).

Despite well-documented negative outcomes, other scholars have stressed the positive sides of social media, emphasising its possibilities for empowerment (Barnard, 2016; Kedzior et al., 2016; Tiidenberg \& Gómez Cruz, 2015, see also Ảberg \& Salonen in this book) and gratification for people who might otherwise suffer from low self-esteem. Pounders et al. (2016) claimed that improving one's self-esteem is simultaneously a motivator for as well as the outcome of the practice of selfie-posting. Previous studies have stated that positive feedback is especially important for female millennials (Pounders et al., 2016).

This chapter aims to elaborate on this 'online Ouroboros', by focusing on whether appearance dissatisfaction leads to an increased tendency to post content on social media and seek gratification from one's peers. We reverse the previous assumptions that social media is a one-sided source of appearance concerns by approaching it from the viewpoint of the outcome (that is, for example, appearance dissatisfaction) being the motivator for downloading content. Previous research has identified the gendered differences in the consumption of social media content (e.g. Koiranen et al., 2019) as well as the gendered effects of social media on psychological well-being (e.g. Mills et al., 2018; Tiggemann \& Barbato, 2018). Still, relatively little is known about how appearance satisfaction is related to the creation of social media content. Moreover, we do not know whether appearance dissatisfaction is associated with an increased or decreased propensity to create content on social media to firstly test, but also verify the value of one's capitals. To address these gaps in research, this study offers insights into the discussion on the relationship between physical appearance and social media use.

We analysed overall appearance satisfaction, and the effects of facial and body satisfaction separately, to determine whether they result differently in employing social media affordances. Additionally, previous research has generally been conducted through experimental designs with small and unrepresentative samples, and there is (to our knowledge) no previous research that can be explicitly generalised to broader populations. The novelty value of our study hence lies in turning previous research designs the other way around: assessing appearance 
satisfaction as a predictor of content creation, as well as using nationally representative data.

This study draws mainly from two perspectives that have been used predominantly to explain the effects of social media on female body image: social comparison theory (Festinger, 1954) and objectification theory (Fredrickson \& Roberts, 1997). The former refers to women comparing themselves with unrealistic and idealised media images that result in body and appearance dissatisfaction (Levine \& Murnen, 2009; Want, 2009). The latter refers to socialising women to internalise an observer's perspective on themselves and come to view themselves in objectified terms (for a review, see Tiggemann, 2011).

This chapter elaborates on these previous claims further, first, by assessing how appearance satisfaction predicts content creation on social media. Second, we examine the differences between Facebook and Instagram users on how appearance satisfaction affects content creation. Last, we ask about the extent to which the detected associations are gendered. Before turning to the empirical analysis, we formulate the hypotheses for these research questions based on previous theoretical literature and research findings. We then present our data and methods. Finally, we discuss whether content creation has an impact on appearance (dis)satisfaction and feeds the online Ouroboros of appearance society, rather than offers a release from it. Additionally, we discuss the role of different social networking platforms, as well as gender differences in appearanceinduced inequality on social media.

\section{Hypotheses Development}

\section{Appearance Satisfaction and Content Creation}

Previous empirical studies on content creation are focused mainly on selfies and their relation to self-esteem. In a study by Pounders et al. (2016), participants revealed that, rather than striving to appear authentic and real, the informants indicated a desire to portray themselves as living happy lives and displaying positive physical self-images, regardless of their internal feelings. The initial motivator for posting selfies was impression management, and informants disclosed posting both genuine and non-genuine posts to manage the impression of happiness and physical appearance. Findings also showed that self-esteem plays an integral role in understanding selfie-posting, and the number of 'likes' can positively or negatively affect the person's self-esteem.

In other words, taking and posting happy selfies can provide a self-esteem boost, regardless of the initial mindset of the person posting them (Kedzior et al., 2016), pointing to the empowering potential of social media and selfies. As networked technologies allow for capturing and sharing embodied experience (Tiidenberg \& Gómez Cruz, 2015), social media can empower its users. Moreover, taking and sharing selfies offers groups that have previously been objectified and denied agency possibilities to challenge their public portrayal (Barnard, 2016). However, the very same studies have also suggested that such empowerment includes a threat to self-esteem, as it requires constant validation from 


\section{Erica Åberg and Aki Koivula}

others in the form of likes, retweets and comments. This conditional provision of validation may start to arouse the need to perform in specific ways to meet the audience's expectations to receive the aforementioned comments and likes (Tiidenberg \& Gómez Cruz, 2015). Seeking validation from peers and its effect on self-esteem can be seen as a perfect illustration of what is described in Fredrickson and Roberts's (1997) objectification theory. The theory claims that the pervasiveness of sexual objectification gradually socialises women and girls to internalise an observer's perspective of their bodies and view themselves as an object to be looked at and evaluated based on appearance.

Despite the possibilities for self-presentation, as well as empowerment and broader appearance ideals, the online presentations of other people in general predominantly promote such attributes as youthfulness and thinness. Fulfilling these appearance ideals is impossible to achieve for most women, who are said to be vulnerable to body dissatisfaction, particularly concerning body shape and weight (Groesz et al., 2002; Tiggemann \& Slater, 2013). The most often used and generally accepted framework for understanding the prevailing body dissatisfaction of women is the sociocultural theory, which claims that contemporary beauty ideals are reinforced and sustained by sociocultural influences, most notably parents, peers and media (e.g. Thompson et al., 1999). These sociocultural ideals are hard to overcome individually: if the source is flawed, it cannot be fixed by retouching one's photos. A study by Shome et al. (2020) established that the opportunity to retake and modify selfies before posting them on social media predicted a decrease in the participant's social anxiety. However, other negative outcomes, like decreased feelings of self-confidence and the desire to undergo cosmetic surgery, were higher among the participants who had an option to retouch their selfies. These findings were partly consistent with the conclusion of Mills et al. (2018), who correspondingly observed that taking and uploading selfies resulted in negative feelings: decreased confidence and feelings of anxiety, irrespective of the opportunity to edit the selfie.

The above-cited studies focus on selfie-related behaviours and appearance concerns but speak in terms of general appearance. Other studies have distinguished between facial and body dissatisfaction, and claim that individuals who have greater body satisfaction are, to begin with, more likely to engage in posting selfies (Ridgway \& Clayton, 2016). Cohen et al. (2018) found similar associations in their study. However, as selfies predominantly include portrait photos rather than full-bodied images, it may be that the relationships between appearance concerns and selfie-related behaviours may contribute more to facial appearance dissatisfaction than to body dissatisfaction. Moreover, it has been stated that taking and editing of selfies leads to experiences of more negative mood and resulted especially in facial dissatisfaction (Tiggemann et al., 2020b). Similarly, viewing idealised selfies with makeup on social media specifically influenced women's face appearance concerns, rather than concerns about their overall physical appearance (Fardouly \& Rapee, 2019). A more extensive approach was found in Wang et al. (2019), establishing a reciprocal relationship among selfierelated behaviours, associating them with self-objectification and appearance concerns among adolescents. Their results indicate that selfie-editing, but not 
selfie-posting, predicted an increase in adolescents' self-objectification and appearance concerns (both body and face) over time. However, selfie-viewing predicted increases in self-objectification and facial dissatisfaction, but not body dissatisfaction, over time. Moreover, participants' facial dissatisfaction positively predicted selfie-viewing and selfie-editing, whereas body dissatisfaction did not influence subsequent selfie-related behaviours.

To our knowledge, only a few studies (e.g. Ridgway \& Clayton, 2016; Wang et al., 2019) have explicitly examined the interconnection of distinguished appearance dissatisfaction and selfie practices. However, despite stressing the central role of appearance dissatisfaction in selfie-related behaviour, only bodily dissatisfaction has been associated with an increased tendency for selfie-posting in these studies. Thus, we use our data to investigate whether body dissatisfaction or facial dissatisfaction predicts content creation in overall, not just selfies, differently on social media.

With this previous research and their findings in mind, we assume that social media increases self-objectification and social comparison that results in appearance (dis)satisfaction, which predicts content creation. Thus, we propose the following hypotheses: People who are less satisfied with their facial appearances create more content on social media than those who are satisfied with their facial appearances (H1.1). Second, people who are less satisfied with their bodily appearances create more content on social media, compared to those who are satisfied with their bodily appearances (H1.2).

\section{Appearance Satisfaction and Content Creation on Different Social Media Platforms}

Previous research has found several differences among social networking sites, in terms of the method of interaction, self-presentation and importantly, the types of social ties that those different platforms allow. As social media platforms have been designed for specific user purposes and are structured in varied ways, their user profiles differ accordingly. Like other countries, in Finland, active social media use and content generation are more common among women and young people (Ertiö et al., 2018). Young people on Instagram are highly focused on selfpresentation through visual means and aim to control how others receive them or their tastes (Sheldon \& Bryant, 2016).

When it comes to platform-specific features, Instagram, compared to other social media sites, is based on embodying one's identity. 'Selfies', i.e. photographs people take of themselves, are abundant on Instagram (Ridgway \& Clayton, 2016). Based on its visuality, studies have found negative consequences for engaging in the appearance-related features of social media. For example, a metaanalysis by Mingoia et al. (2017) found that internalisation of sociocultural ideals, such as thinness, is mainly associated with posting and viewing images on social media.

Moreover, social media platforms are also distinguished by their social nature. Facebook is based more on social interaction, which focuses on reciprocity between individuals, as well as consent to social bonding. Facebook is more like 


\section{Erica Åberg and Aki Koivula}

an extension of social life outside the Internet, as its users form social ties with people who they typically have known from real life (Manzi et al., 2018). Social interaction on the platform is also more social and reciprocal: on Facebook, people belong to groups with like-minded people or those who are interested in the same things. Moreover, Facebook has become increasingly popular as a market platform for peer-to-peer trade with other users, peers, on Facebook. (Lee et al., 2014).

In contrast to Facebook, on Instagram, a profile can be public and thus, not requiring approval from the person followed. Hence, Instagram invites being followed by and, in particular, following of strangers, including celebrities (cf. Lup et al., 2015.). As a result, increasing the size of different networks, as well as increased visibility, is easier on Instagram Phua et al. (2017). However, the quality of networks may be different on Instagram, where one-sided following is more likely to occur, which also means that information flows in only one direction. Instagram is also more performative than Facebook; it is not based on information-sharing or other social reciprocity in the same way as Facebook. Given its visual nature, it can be seen as focusing more specifically on selective self-presentation and performative identities (e.g. boyd, 2008; Dobson, 2016), as well as more niched performances, such as 'doing pregnancy' (Tiidenberg \& Baym, 2017). Moreover, the content can also be tagged and thus made available to the so-called 'attention economy' (Marwick, 2015, see also Åberg \& Salonen in this book) prominent on social media. Besides tagging one's content, tagging, but also sharing publicly available content, for example, cute animals or funny memes, can be seen as a type of performance in and of itself (e.g. Tiidenberg \& Baym, 2017).

As previous studies have indicated, Instagram allows for a selective selfpresentation, more performative use and, potentially, a more extensive network. Thus, we hypothesise that the relationship between appearance (dis) satisfaction and content creation is more prominent among Instagram users when compared to the users of other social media platforms $(\mathrm{H} 2)$.

\section{Appearance Satisfaction, Content Creation, Social Media Platforms and Gender}

Most of the previously presented findings are consistent with the prediction of Fredrickson and Roberts's objectification theory (1997) that engaging in a selfobjectifying activity (like selfie posting) results in worsened body image outcomes for women. This theory claims that sexual objectification in contemporary society socialises girls and women to treat themselves as objects to be looked upon and evaluated based upon bodily appearance, leading to four negative subjective experiences: body shame, appearance anxiety, diminished peak motivational status and reduced connection with one's internal bodily states (Fredrickson \& Roberts, 1997). In addition to self-objectification, body image disturbances and appearance concerns of women are often approached with social comparison theory (Festinger, 1954). According to social comparison theory, people seek to compare their appearances with prevailing social standards, including the 
appearance standards presented in the media. Making evaluative comparisons between their appearance and the idealised and artificially created appearance of women in the media, most women are likely to feel they need to meet that standard. Due to that shortage, female viewers typically end up feeling dissatisfied with their appearance.

From subjective experiences, Terán et al. (2019) identified body shame and appearance anxiety as the most relevant to the potential consequences of selfies for women. Similarly, Tiggemann and Barbato (2018) claimed that objectification theory may be particularly relevant in the context of a photographic social media site like Instagram, with its primary function being posting photos of oneself for others to look and comment. According to their study, women's body dissatisfaction increased in response to viewing images and posted comments on Instagram. In addition to self-objectification, it has been established that social networking sites are associated with upward social comparison and lowered feelings for women (e.g. Fox \& Vendemia, 2016). Moreover, contemporary body ideals on social media have become even more unattainable for most women: relatively thin, but also toned and strong (Tiggemann \& Zaccardo, 2018). Although most of these previous studies have focused on women, social media has an impact on men also, reproducing stereotypical norms of masculinity in the form of embodying strength and power (Fox \& Vendemia, 2016), and it forces men to increasingly rely on their bodies for personal value creation (Hakim, 2015, see also Sarpila in this book).

Moreover, men and women differ in their social media practices. Whereas women typically use social media more actively and are more likely to use social media to view others' photos (Smith, 2014), as well as compare themselves with others, men are more likely to use social media to find or contact friends (Haferkamp et al., 2012). Social networking sites allow for self-conspicuousness, and young women, in particular, present idealised images of themselves on social media (Dhir et al., 2016). Consequently, other young women see these idealised images of their peers and compare themselves with them, causing appearancerelated distress (e.g. Holland \& Tiggemann, 2016). A recent study found that active social media usage with attractive peers on appearance-based social media resulted in worsened body image for young adult women, whereas interacting with members of the family did not affect body image (Hogue \& Mills, 2019).

Moreover, living up to prevailing appearance norms is effectively ensured on social media, where followers, 'likes' and positive appearance comments on uploaded content can be seen as rewarding appearance ideals. Prior research reveals a tendency for women to both receive and give compliments on appearance (Åberg, Koivula, Kukkonen, Sarpila, \& Pajunen, 2020; Holmes, 1998) and well as place a higher premium on receiving those comments. These gendered commenting norms tend to reinforce the norm of placing even more emphasis on and directing the viewer's focus to women's appearances.

Following these strands of literature, we formulate the next hypotheses: Women who are less satisfied with their appearances create more content on Instagram than equally satisfied men (H3.1). Second, appearance (dis) satisfaction is not associated with men's content creation on social media (H3.2). 


\section{Erica Åberg and Aki Koivula}

\section{This Study}

In sum, this study aims to investigate the effect of facial and body satisfaction on social media content creation. Based on previous research, we predict that appearance (dis)satisfaction drives the creation of more content. Moreover, we assume that the relationship between appearance dissatisfaction and content creation is more salient among women, and especially prominent on Instagram. Next, we proceed to our data and present our analysis strategy before unpacking the results of the analysis.

\section{Participants}

Our data were derived from the survey 'Finland in the digital age' (Sivonen et al., 2018), that included a total of 3,724 respondents. The survey data were collected in two parts, using two different sampling methods. First, the survey reached a total of 2,470 participants aged 18-74 years, who were from the initial group of 8,000 Finnish-speakers sampled randomly from the Finnish census. Additionally, the data were improved with 1,254 participants (also aged 18-74 years) from a nationally representative online panel of volunteer respondents administrated by a market research company.

Although the total share represents relatively well the share of the Finnish population, older users were slightly overrepresented. Consequently, the data were post-stratified in terms of age and gender distribution to correspond with the official population distribution in Finland according to the Official Statistics of Finland.

In this study, the analyses were based on social media users, totalling 2,761 respondents who comprise $74 \%$ of the total data. Our final study sample included 1, 319 women $(47 \%)$ and the mean age was $47.7(\mathrm{SD}=15.8)$.

\section{Measures}

The applied measures are shown in Table 1. The dependent variable measured how often respondents shared their own created content on social media. The item was a part of a question battery in which we asked a total of 14 subquestions, with a question: 'How often do you do the following?'. The responses and their distribution were 1 'Never' (22.9\%), 2 'Less than weekly' (51.4\%), 3 'Weekly' (22.5\%) and 4 'Daily' (3.2\%). Only $0.7 \%$ of the answers were missing. In the analysis, we focused on predicting active content creation. We dichotomised the variable into a binary, in which 1 differentiates those who created content at least weekly $(25.7 \%)$ from those who created content less than weekly $(74.3 \%)$.

The main predictor variables were satisfaction with bodily appearance and satisfaction with facial appearance. The dimensions were explored separately with the same main question, namely, 'How satisfied are you with (a) your face (b) your body?' The responses were scored with a 5-point interval scale, in which 1 was labelled as 'Not content at all' and 5 was 'Very content'. 
Table 7.1. Descriptive Statistics of Applied Variables.

\begin{tabular}{lccc}
\hline Variable & Obs & Mean/\% & Std. Dev. \\
\hline Content creation & 2,726 & & \\
No & & 0.74 & 0.44 \\
Yes & 2,748 & 0.26 & 0.44 \\
Body satisfaction & 2,749 & 3.30 & 0.99 \\
Facial satisfaction & 2,761 & 3.63 & 0.87 \\
Social network site & & & \\
Other & & 0.17 & 0.38 \\
Only Facebook & & 0.41 & 0.49 \\
Instagram & 2,753 & 0.42 & 0.49 \\
Gender & & & \\
Male & & 0.48 & 0.50 \\
Female & 0.52 & 0.50 \\
\hline
\end{tabular}

The moderating variables were the preferred social network site (SNS) and gender. Initially, gender was queried via three categories. However, we had just one observation from individuals other than men or women social media users, and consequently, we excluded the 'other' category from further analyses. In terms of SNS, we paid especially attention to differences between the users of Facebook and Instagram by differentiating the respondents who used both Facebook and Instagram or just Instagram, from those who only used Facebook. We also filtered those who did not use Facebook or Instagram at all but use some other platform(s) into the category 'Else'. Accordingly, the final variable labelled as 'The preferred SNS' had three categories, namely, 1 'Only Facebook', 2 'Instagram', 3 'Else'.

\section{Analysis Strategy}

The analysis was performed with Stata 16. First, we conducted logit models to predict the probability of creating content on social media at least weekly, according to satisfaction with facial and body appearance. Next, we focused on the moderating effect of the preferred SNS. We added an interaction term 'the preferred SNS $\times$ appearance satisfaction' into the base model. Finally, we continued the procedure and added the interaction term 'the preferred SNS $\times$ appearance satisfaction $\times$ gender' to determine whether the effect of appearance satisfaction is potentially gendered.

Instead of presenting odds ratios from the logit models, we estimated the predicted probabilities that describe the adjusted percentage point estimates of the differences in the outcome variables, according to the different levels of predicting 


\section{Erica Åberg and Aki Koivula}

variables (Muller \& MacLehose, 2014). We illustrated the predicted probabilities into the figures by utilising the user-written coefplot-package (Jann, 2014). In each figure, the $y$-axis describes the probability of content creation at the different levels of appearance satisfaction indicated at the x-axis. The results of interaction analyses were presented by plotting the relationship between appearance satisfaction and content creation for each moderating variable.

\section{Results}

We began an analysis by examining how appearance satisfaction predicts the likelihood of creating content on social media. Our main expectation was that those users who were less satisfied with their appearance create more content on social media. By considering recent studies (e.g. Cohen et al., 2018; Ridgway \& Clayton, 2016), we also distinguished facial and body appearance. To find mechanisms that explain active behaviour on social media, we targeted our model to estimate how likely it is that users create content at least weekly.

The results of analysis partly confirmed our hypotheses. First, people who were dissatisfied with their bodily appearance had a higher probability of creating content, as we expected. The predicted probabilities shown in Fig. 7.1 indicate that the probability of content creation may decrease by 15 percentage points between dissatisfied and satisfied. Against our expectations and literature emphasising the emergence of facial dissatisfaction due to selfie-related practices,

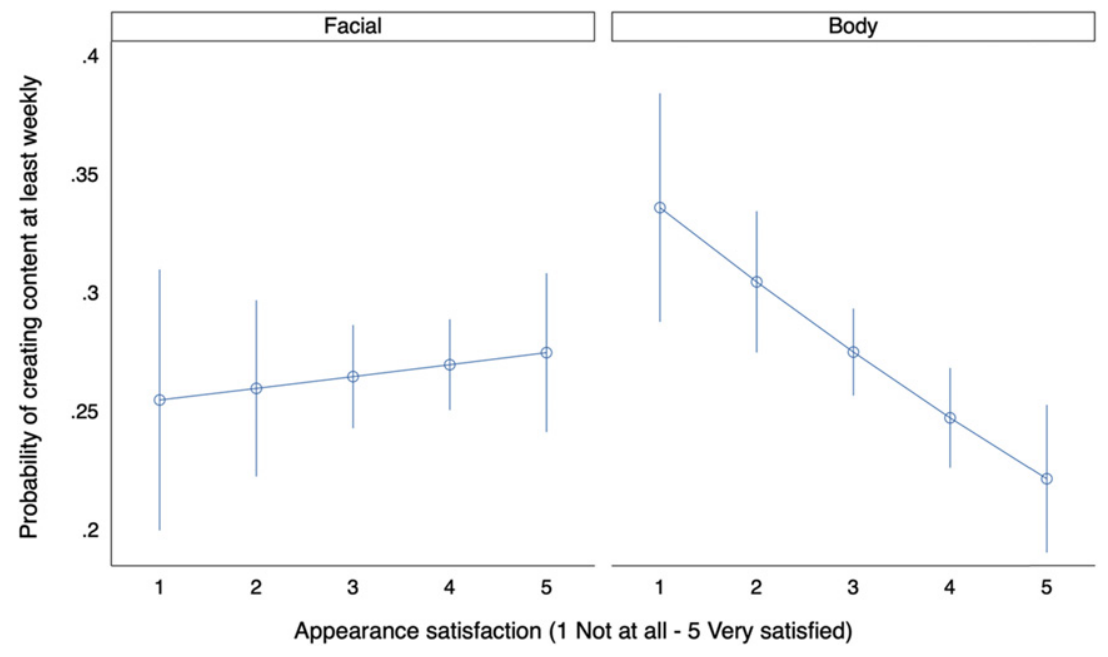

Fig. 7.1. The Likelihood of Creating Content on Social Media According to Appearance Satisfaction. Predicted probabilities with confidence intervals $(95 \%)$. The y-axis describes the probability of content creation and the $\mathrm{x}$-axis describes facial and body satisfaction. 
we could not find that satisfaction with facial appearance is associated with the probability of creating and sharing content on social media.

Next, we continued the analysis to determine whether the effect of appearance satisfaction is dependent on the social network site users prefer. We assumed that the effect or interconnection of appearance dissatisfaction and content creation is more prominent on Instagram, which is the most visual platform in this comparison. We focused solely on the effect of body satisfaction revealed as significant in the first analysis. The results presented in Fig. 7.2 confirmed our assumption and indicated that the effect of appearance satisfaction is particularly strong on content creation on Instagram. Those users who were less satisfied with their appearance were more likely to create content. To underline our expectations, we did not observe effects of body satisfaction on content creation among Facebook users. Among the users of other platforms, the effect of appearance satisfaction was almost positive, i.e. the opposite of that on Instagram.

The third part of the analysis concentrates on the gendered patterns of Instagram users. We proposed two separate hypotheses: First, we assumed that women who are less satisfied with their appearances create more content on social media. Second, we expected that appearance concerns do not drive men to create content on social media. The results partly confirmed our hypotheses. Fig. 7.3 indicates that those women who were not satisfied with their body appearance were more likely to create content on social media than equally satisfied men. In contrast to our hypothesis, we could not find a significant interaction effect of

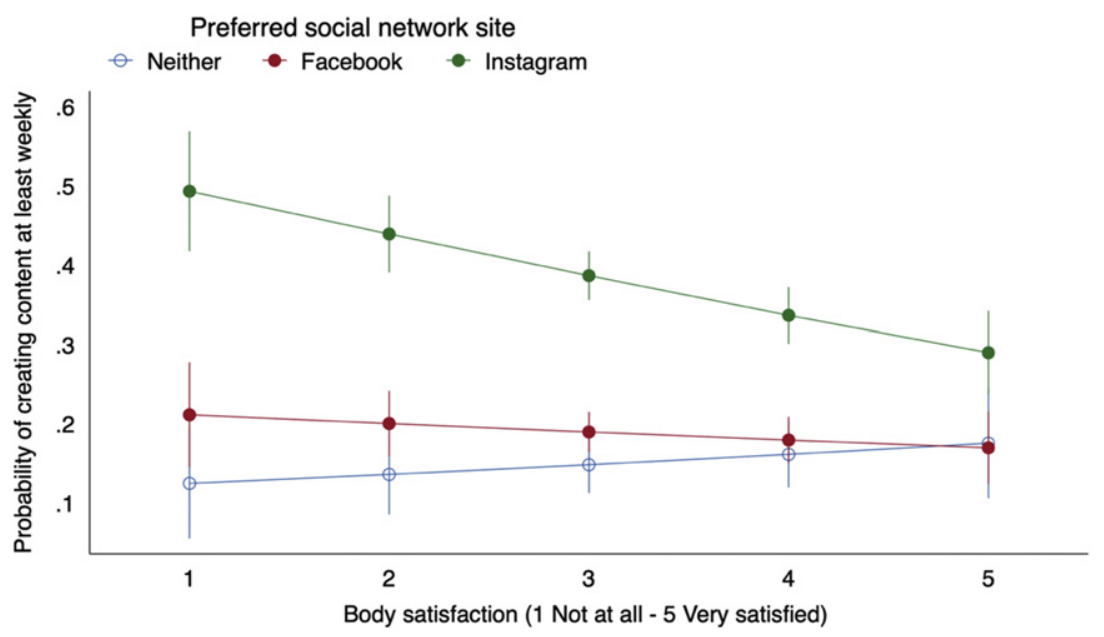

Fig. 7.2. The Relationship between Creating Content and Body Satisfaction According to the Preferred Social Network Site. Predicted probabilities with confidence intervals $(95 \%)$. The y-axis describes the probability of content creation and the x-axis describes body satisfaction. 


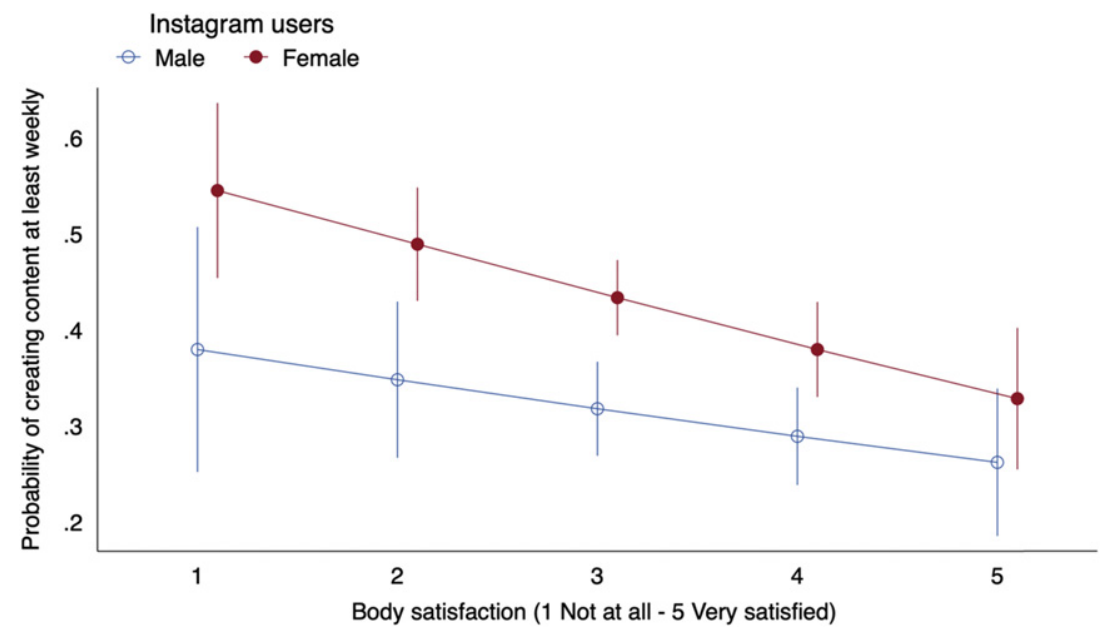

Fig. 7.3. The Relationship between Creating Content and Body Satisfaction According to Gender among Instagram Users. Predicted probabilities with confidence intervals $(95 \%)$. The y-axis describes the probability of content creation and the $\mathrm{x}$-axis describes body satisfaction.

gender, as the effect of body satisfaction was also, although not significant, negative among men.

\section{Discussion}

This study elaborated on how appearance satisfaction predicts content creation on social media, and how aesthetic capital is negotiated on those platforms. We also examined the differences between different platforms and finally assessed whether the detected associations are gendered.

The results of a representative survey partly confirmed our first hypotheses. We found that content creation is related to body satisfaction of social media users, but not to facial satisfaction. This finding was consistent with Ridgway and Clayton's (2016) findings, but inconsistent with those of Wang et al. (2019), who posited that participants' facial dissatisfaction predicted selfie-viewing and selfieediting but not selfie-posting over time, whereas body dissatisfaction did not influence subsequent selfie-related behaviours.

We assume that, despite not being in line with previous studies, our results indicate that especially visual social media platforms, such as Instagram, allow for more facial diversity, but are still evolving on bodily variance. In light of objectification theory (Fredrickson \& Roberts, 1997), as well as social comparison theory (Festinger, 1954; Fardouly et al., 2015), our findings can be interpreted as an indication of bodies being different from faces. They are theoretically more 
'manageable' and thus, offer more possibilities from which to experience pressures. Furthermore, unsatisfying bodies are easier to cover up with complementary clothing, or in the context of social media, possibly smoothed with filters. Moreover, as previous research has mainly concentrated on selfies, it seems noteworthy too that selfies seldom include full-body images. Thus, selfie-related behaviours and appearance concerns may contribute more to facial appearance concerns (see Cohen et al., 2018), rather than eliciting concerns about overall physical appearance (Fardouly \& Rapee, 2019).

The second analysis confirmed our hypothesis that the relationship between appearance satisfaction and content creation is prominent among Instagram users. As an image-based and visual platform, Instagram provides a favourable base for appearance-driven content creation (Ridgway \& Clayton, 2016). We also suggest that algorithms may influence the emergence of appearance pressures on Instagram. Instagram may suggest content that is visually similar to those previously watched or created, even though the user is capable of blocking pressuring content (Cotter, 2019), making the platform more unpredictable and manageable for social media users.

Finally, in terms of our third hypothesis, the results suggested that women's activity on social media is more likely to be associated with appearance satisfaction compared to activity among male users. This outcome is in line with Fredrickson and Roberts's objectification theory (1997), which claims that sexual objectification in contemporary society socialises girls and women to treat themselves as objects to be looked upon and evaluated based upon bodily appearance. Thus, any self-objectifying activity, such as selfie-posting, results in worsened body image, appearance dissatisfaction, shame and anxiety (ibid., see also Terán et al., 2019; Tiggemann \& Barbato, 2018). We can conclude that these feelings are associated with sharing content, and they encourage women to seek validation from their online community. However, instead of experiencing personal empowerment, they may end up feeding the Ouroboros of appearanceoriented society that is forcing them to create more, better and different content than other people.

Overall, our results are in line with theories that associate social media with the heightened tendency for social comparisons and upward appraisals (Leahey et al., 2007; McMullin \& Cairney, 2004) that reinforce the socially constructed, normative ideals of beauty. Elaborating this in light of the overall topic of this book, social media is an accelerator of appearance-oriented society. Moreover, prior research has revealed a tendency for women to both receive and give compliments on appearance (Åberg, Koivula, Kukkonen, Sarpila, \& Pajunen, 2020; Holmes, 1998), as well as place a higher premium on receiving such comments. These gendered commenting norms contribute to the gendered differences, emphasising women's appearances, making them feel even more on display and pressured to look good. There have been occasional attempts to contest the objectifying nature of social media by, for example, adding self-compassion statements (Lonergan et al., 2019). However, Tiggemann et al. (2020a) suggested that presenting a more diverse array of women's bodies on social media is likely a more effective way to foster body satisfaction and appreciation than 


\section{Erica Åberg and Aki Koivula}

textual contestation of prevailing appearance norms that place more emphasis on looks.

Finally, we present two separate but overlapping directions for future research. First, future research should consider how appearance concerns may result in a different kind of disordered behaviour on social media. Previous research has already found that active social media use with body image concerns is related to disordered offline behaviour, such as disordered eating (e.g. Holland \& Tiggemann, 2016). In this respect, it is also possible that frequent content creation driven by appearance dissatisfaction is related to problematic use of social media. Moreover, previous research has found conflicting results for online selfcompassion statements (Lonergan et al., 2019) and body-positive captions (Tiggemann et al., 2020a) on visual imagery and their relationship to body dissatisfaction. This discrepancy should be studied more: Which contributes more potently to appearance dissatisfaction, the idealised image or the textual content? Acknowledging the discrepancy may help to solve the perpetual motion machine or the online Ouroboros that encourages individuals, first, to create content, but also to seek gratification, on social media. Moreover, it could help understanding the ways of, but also motivations for, accumulating different capitals online, and how those ways are related to existing inequalities.

Naturally, our study has limitations. First, according to our dependent variable, we could not interpret what kind of content creation was associated with appearance satisfaction. Our measure covered all the activities that users have engaged in on social media, even though previous studies have generally focused solely on the production and sharing of selfies (e.g. Pounders et al., 2016). In this respect, future studies should use more accurate measures of social media behaviour to determine outcomes of appearance satisfaction. Second, it is important to acknowledge that we used cross-sectional data that did not enable causal inferences. Therefore, we suggest that future studies should use longitudinal data sets to investigate whether appearance satisfaction predicts content creation over time.

\section{References}

Barnard, S. R. (2016). Spectacles of self (ie) empowerment? Networked individualism and the logic of the (post) feminist selfie. In Communication and information technologies annual. Emerald Publishing Limited. https://doi.org/10.1108/S2050206020160000011014

boyd, D. (2008). Why youth (heart) social network sites: The role of networked publics in teenage social life. In D. Buckingham (Ed.), Youth, identity, and digital media. The John D. and Catherine T. MacArthur foundation series on digital media and learning. The MIT Press, 2007-2016.

Cohen, R., Newton-John, T., \& Slater, A. (2018). 'Selfie'-objectification: The role of selfies in self-objectification and disordered eating in young women. Computers in Human Behavior, 79, 68-74. https://doi.org/10.1016/j.chb.2017.10.027 
Cotter, K. (2019). Playing the visibility game: How digital influencers and algorithms negotiate influence on Instagram. New Media \& Society, 21(4), 895-913. https:// doi.org/10.1177/1461444818815684

Dhir, A., Pallesen, S., Torsheim, T., \& Andreassen, C. S. (2016). Do age and gender differences exist in selfie-related behaviours?. Computers in Human Behavior, 63, 549-555. https://doi.org/10.1016/j.chb.2016.05.053

Dobson, A. S. (2016). Postfeminist digital cultures: Femininity, social media, and selfrepresentation. Springer.

Ertiö, T., Kukkonen, I., \& Räsänen, P. (2018). Social media activities in Finland: A population-level comparison. Convergence, 26(1), 193-209. https://doi.org/10.1177/ 1354856518780463

Fardouly, J., Diedrichs, P. C., Vartanian, L. R., \& Halliwell, E. (2015). Social comparisons on social media: The impact of Facebook on young women's body image concerns and mood. Body Image, 13, 38-45. https://doi.org/10.1016/j.bodyim.2014. 12.002

Fardouly, J., \& Rapee, R. M. (2019). The impact of no-makeup selfies on young women's body image. Body Image, 28, 128-134. https://doi.org/10.1016/j.bodyim. 2019.01.006

Featherstone, M. (1982). The body in consumer culture. Theory, Culture \& Society, 1(2), 18-33. https://doi.org/10.1177/026327648200100203

Festinger, L. (1954). A theory of social comparison processes. Human relations, 7(2), 117-140. https://doi.org/10.1177/001872675400700202

Fox, J., \& Vendemia, M. A. (2016). Selective self-presentation and social comparison through photographs on social networking sites. Cyberpsychology, Behavior, and Social Networking, 19(10), 593-600. https://doi.org/10.1089/cyber.2016.0248

Fredrickson, B. L., \& Roberts, T. A. (1997). Objectification theory: Toward understanding women's lived experiences and mental health risks. Psychology of Women Quarterly, 21(2), 173-206. https://doi.org/10.1111/j.1471-6402.1997.tb00108.x

Groesz, L. M., Levine, M. P., \& Murnen, S. K. (2002). The effect of experimental presentation of thin media images on body satisfaction: A meta-analytic review. International Journal of Eating Disorders, 31(1), 1-16. https://doi.org/10.1002/ eat. 10005

Haferkamp, N., Eimler, S. C., Papadakis, A. M., \& Kruck, J. V. (2012). Men are from mars, women are from venus? Examining gender differences in self-presentation on social networking sites. Cyberpsychology, Behavior, and Social Networking, 15(2), 91-98. https://doi.org/10.1089/cyber.2011.0151

Hakim, J. (2015). 'Fit is the new rich': Male embodiment in the age of austerity. Soundings, 61(61), 84-94. https://doi.org/10.3898/136266215816772197

Hogue, J. V., \& Mills, J. S. (2019). The effects of active social media engagement with peers on body image in young women. Body Image, 28, 1-5. https://doi.org/ 10.1016/j.bodyim.2018.11.002

Holland, G., \& Tiggemann, M. (2016). A systematic review of the impact of the use of social networking sites on body image and disordered eating outcomes. Body Image, 17, 100-110. https://doi.org/10.1016/j.bodyim.2016.02.008

Holmes, J. (1998). Complimenting: A positive politeness strategy. In J. Coates (Ed.), Language and gender: A reader (pp. 100-120). Blackwell Publisher Ltd. 


\section{Erica Åberg and Aki Koivula}

Jann, B. (2014). Plotting regression coefficients and other estimates. The Stata Journal, 14(4), 708-737. https://doi.org/10.1177/1536867X1401400402

Kedzior, R., Allen, D. E., \& Schroeder, J. (2016). The selfie phenomenon-consumer identities in the social media marketplace. European Journal of Marketing, 50(9/10), 1767-1772. https://doi.org/10.1108/EJM-06-2016-0363

Koiranen, I., Keipi, T., Koivula, A., \& Räsänen, P. (2019). Changing patterns of social media use? A population-level study of Finland. Universal Access in the Information Society, 1-15. https://doi.org/10.1007/s10209-019-00654-1

Leahey, T. M., Crowther, J. H., \& Mickelson, K. D. (2007). The frequency, nature, and effects of naturally occurring appearance-focused social comparisons. Behavior Therapy, 38(2), 132-143. https://doi.org/10.1016/j.beth.2006.06.004

Lee, M. R., Yen, D. C., \& Hsiao, C. Y. (2014). Understanding the perceived community value of Facebook users. Computers in Human Behavior, 35, 350-358. https://doi.org/10.1016/j.chb.2014.03.018

Levine, M. P., \& Murnen, S. K. (2009). "Everybody knows that mass media are/are not [pick one] a cause of eating disorders": A critical review of evidence for a causal link between media, negative body image, and disordered eating in females. Journal of Social and Clinical Psychology, 28(1), 9-42. https://doi.org/10.1521/jscp.2009. 28.1.9

Lonergan, A. R., Bussey, K., Mond, J., Brown, O., Griffiths, S., Murray, S. B., \& Mitchison, D. (2019). Me, my selfie, and I: The relationship between editing and posting selfies and body dissatisfaction in men and women. Body Image, 28, 39-43. https://doi.org/10.1016/j.bodyim.2018.12.001

Lup, K., Trub, L., \& Rosenthal, L. (2015). Instagram\# instasad?: Exploring associations among instagram use, depressive symptoms, negative social comparison, and strangers followed. Cyberpsychology, Behavior, and Social Networking, 18(5), 247-252. https://doi.org/10.1089/cyber.2014.0560

Manzi, C., Coen, S., Regalia, C., Yévenes, A. M., Giuliani, C., \& Vignoles, V. L. (2018). Being in the social: A cross-cultural and cross-generational study on identity processes related to Facebook use. Computers in Human Behaviour, 80, 81-87. https://doi.org/10.1016/j.chb.2017.10.046

Marwick, A. E. (2015). Instafame: Luxury selfies in the attention economy. Public Culture, 27(1-75), 137-160. https://doi.org/10.1215/08992363-2798379

McMullin, J. A., \& Cairney, J. (2004). Self-esteem and the intersection of age, class, and gender. Journal of Aging Studies, 18(1), 75-90. https://doi.org/10.1016/ j.jaging.2003.09.006

Mills, J. S., Musto, S., Williams, L., \& Tiggemann, M. (2018). "Selfie” harm: Effects on mood and body image in young women. Body Image, 27, 86-92. https://doi.org/ 10.1016/j.bodyim.2018.08.007

Mingoia, J., Hutchinson, A. D., Wilson, C., \& Gleaves, D. H. (2017). The relationship between social networking site use and the internalisation of a thin ideal in females: A meta-analytic review. Frontiers in Psychology, 8, 1351. https://doi.org/10.3389/ fpsyg.2017.01351

Muller, C. J., \& MacLehose, R. F. (2014). Estimating predicted probabilities from logistic regression: Different methods correspond to different target populations. International Journal of Epidemiology, 43(3), 962-970. https://doi.org/10.1093/ije/ dyu029 
Phua, J., Jin, S. V., \& Kim, J. J. (2017). Uses and gratifications of social networking sites for bridging and bonding social capital: A comparison of Facebook, Twitter, Instagram, and Snapchat. Computers in Human Behaviour, 72, 115-122. https:// doi.org/10.1016/j.chb.2017.02.041

Pounders, K., Kowalczyk, C. M., \& Stowers, K. (2016). Insight into the motivation of selfie postings: Impression management and self-esteem. European Journal of Marketing, 50(9/10), 1879-1892. https://doi.org/10.1108/EJM-07-2015-0502

Reemes, D. M. (2015). The Egyptian Ouroboros: An iconological and theological study. Doctoral dissertation, UCLA.

Ridgway, J. L., \& Clayton, R. B. (2016). Instagram unfiltered: Exploring associations of body image satisfaction, Instagram\# selfie posting, and negative romantic relationship outcomes. Cyberpsychology, Behavior, and Social Networking, 19(1), 2-7. https://doi.org/10.1089/cyber.2015.0433

Sheldon, P., \& Bryant, K. (2016). Instagram: Motives for its use and relationship to narcissism and contextual age. Computers in Human Behavior, 58, 89-97. https:// doi.org/10.1016/j.chb.2015.12.059

Shome, D., Vadera, S., Male, S. R., \& Kapoor, R. (2020). Does taking selfies lead to increased desire to undergo cosmetic surgery. Journal of Cosmetic Dermatology, 19(8), 2025-2032. https://doi.org/10.1111/jocd.13267

Sivonen, J., Koivula, A., Saarinen, A., \& Keipi, T. (2018). Working papers in economic sociology: Research report on the Finland in the digital age-survey. Working Papers in Economic Sociology. University of Turku.

Smith, A. (2014). What people like and dislike about Facebook. Pew Research Center, 3.

Terán, L., Yan, K., \& Aubrey, J. S. (2019). "But first let me take a selfie": US adolescent girls' selfie activities, self-objectification, imaginary audience beliefs, and appearance concerns. Journal of Children and Media, 14(3), 343-360. https:// doi.org/10.1080/17482798.2019.1697319

Thompson, J. K., Heinberg, L. J., Altabe, M., \& Tantleff-Dunn, S. (1999). Sociocultural theory: The media and society. In Exacting beauty: Theory, assessment, and treatment of body image disturbance (pp. 85-124). American Psychological Association. https://doi.org/10.1037/10312-003

Tiggemann, M. (2011). Mental health risks of self-objectification: A review of the empirical evidence for disordered eating, depressed mood, and sexual dysfunction. In R. M. Calogero, S. Tantleff-Dunn, \& J. K. Thompson (Eds.), Self-objectification in women: Causes, consequences, and counteractions (pp. 139-159). American Psychological Association. https://doi.org/10.1037/12304-007

Tiggemann, M., Anderberg, I., \& Brown, Z. (2020a). \# Loveyourbody: The effect of body positive Instagram captions on women's body image. Body Image, 33, 129-136. https://doi.org/10.1016/j.bodyim.2020.02.015

Tiggemann, M., Anderberg, I., \& Brown, Z. (2020b). Uploading your best self: Selfie editing and body dissatisfaction. Body Image, 33, 175-182. https://doi.org/10.1016/ j.bodyim.2020.03.002

Tiggemann, M., \& Barbato, I. (2018). "You look great!”: The effect of viewing appearance-related Instagram comments on women's body image. Body Image, 27, 61-66. https://doi.org/10.1016/j.bodyim.2018.08.009

Tiggemann, M., \& Miller, J. (2010). The Internet and adolescent girls' weight satisfaction and drive for thinness. Sex Roles, 63(1-2), 79-90. https://doi.org/10.1007/ s11199-010-9789-Z 


\section{Erica Åberg and Aki Koivula}

Tiggemann, M., \& Slater, A. (2013). NetGirls: The Internet, Facebook, and body image concern in adolescent girls. International Journal of Eating Disorders, 46(6), 630-633. https://doi.org/10.1002/eat.22141

Tiggemann, M., \& Zaccardo, M. (2018). 'Strong is the new skinny': A content analysis of\# fitspiration images on instagram. Journal of Health Psychology, 23(8), 1003-1011. https://doi.org/10.1177/1359105316639436

Tiidenberg, K., \& Baym, N. K. (2017). Learn it, buy it, work it: Intensive pregnancy on Instagram. Social Media + Society, 3(1), 1-13. https://doi.org/10.1177/ 2056305116685108

Tiidenberg, K., \& Gómez Cruz, E. (2015). Selfies, image and the re-making of the body. Body \& Society, 21(4), 77-102. https://doi.org/10.1177/1357034x15592465

Wang, Y., Xie, X., Fardouly, J., Vartanian, L. R., \& Lei, L. (2019). The longitudinal and reciprocal relationships between selfie-related behaviors and self-objectification and appearance concerns among adolescents. New Media \& Society, 23(1), 1461444819894346. https://doi.org/10.1177/1461444819894346

Want, S. C. (2009). Meta-analytic moderators of experimental exposure to media portrayals of women on female appearance satisfaction: Social comparisons as automatic processes. Body Image, 6(4), 257-269. https://doi.org/10.1016/ j.bodyim.2009.07.008

Åberg, E., Koivula, A., \& Kukkonen, I. (2020a). A feminine burden of perfection? Appearance-related pressures on social networking sites. Telematics and Informatics, 46, 101319. https://doi.org/10.1016/j.tele.2019.101319

Åberg, E., Koivula, A., Kukkonen, I., Sarpila, O., \& Pajunen, T. (2020b). Compliment rules or compliments rule? A population-level study of appearance commenting norms on social media. In International conference on humancomputer interaction (pp. 16-28). Springer. https://doi.org/10.1007/978-3-03049576-3_2 